\title{
Perlas de sulfato cálcico como tratamiento exitoso tras retirada de osteosíntesis infectada.
}

\author{
DOI: http//dx.doi.ORG/10.37315/SOTOCAV20212865646
}

VILLAR BLANCO A, PÉREZ BLASCO A, CARRATALÁ PÉREZ C, BORRELl CHOVER A, RODRIGO PÉREZ JL.

SERVICIO DE CIRUGÍA ORTOPÉDICA Y TRAUMATOLOGÍA. HOSPITAL UNIVERSITARIO DOCTOR PESET.

\begin{abstract}
Resumen
Una de las complicaciones más temidas por los equipos de traumatología son las infecciones postquirúrgicas. En nuestro trabajo presentamos el caso de una paciente que tras una osteosíntesis de cadera por una fractura pertrocantérea sufre una infección que se resuelve finalmente gracias al tratamiento con perlas de sulfato cálcico recubiertas de antibiótico. Este tratamiento se presenta como una opción a considerar en aquellos casos que no se resuelvan con las terapias convencionales ya que permite una liberación controlada de antibiótico directamente sobre el sitio de infección.
\end{abstract}

\section{Summary}

One of the complications most feared by orthopedic teams is post-surgical infections. In our paper we present the case of a patient who, after a hip osteosynthesis due to a pertrochanteric fracture, suffers an infection that is finally solved thanks to treatment with calcium sulfate beads coated with an antibiotic. This treatment is presented as an option to consider in those cases that are not resolved with conventional therapies since it presents a controlled release of antibiotic directly on the site of infection.

Palabras clave: Infección, osteosíntesis, Sulfato cálcico, Stimulan.

\section{Correspondencia:}

A. Villar Blanco

alfredoviblan.detec@gmail.com 


\section{INTRODUCCIÓN}

Las infecciones en traumatología son un auténtico reto para los cirujanos ortopédicos y una complicación grave de nuestras cirugías.

El objetivo de este trabajo es mostrar la excelente evolución clínica de una paciente con el uso de perlas de sulfato de calcio (Stimulan $®)^{1}$ tras una osteosíntesis de cadera que falló por una infección.

\section{CASO CLINICO}

Mujer de 82 años que acude a puerta de urgencias tras una caída casual. En urgencias es recibida por el equipo de traumatología de guardia que realiza una exploración de la paciente presentando la misma dolor en cadera izquierda acompañado de acortamiento y rotación externa del miembro inferior izquierdo.

Se realizan radiografías $A P$ de pelvis y $A P$ y axial de cadera izquierda que confirman la sospecha de fractura pertrocantérea de cadera izquierda.

La paciente es ingresada tras su consentimiento informado con analgesia en el servicio de traumatología e intervenida a las 24 horas mediante un enclavado cefalomedular tipo Gamma corto. Tras la cirugía la paciente presenta un episodio de anemización que requiere de una transfusión de una unidad de concentrado de hematíes, presentando tras esto un correcto nivel de hemoglobina. Tras 10 días ingresada, y con buen estado general y buena evolución de la herida quirúrgica la paciente es dada de alta permitiendo la carga ayudada de un andador.

La paciente revisada en consultas externas a los 15 días presentando buena evolución de la herida.

Posteriormente coincidiendo con la situación de la pandemia por Covid-19 la paciente no acude a las revisiones programadas en consulta, aunque se realizan controles telefónicos en los que nos indica que está caminando con el andador y con buen control del dolor.

A los 5 meses de la cirugía la paciente acude a urgencias refiriendo dolor en la cadera intervenida asociado a fiebre termometrada de $39^{\circ}$; a la exploración la herida quirúrgica está cerrada pero hay un claro aumento de temperatura local acompañado de eritema; por la sospecha de infección se ingresa para tratamiento antibiótico y se solicitan analíticas con marcadores de infección y radiografías de la cadera intervenida, las analíticas muestran aumento de los parámetros de infección y las radiografías muestran un fallo del implante por cut-out (Fig.1 y 2) Durante el ingreso se procede a la retirada del material de osteosíntesis aislándose en las muestras quirúrgicas Escherichia Coli.
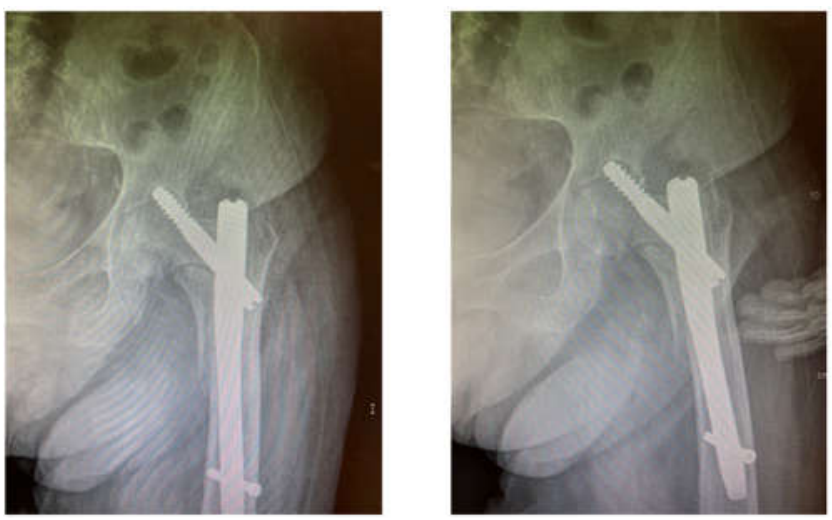

Figuras 1 y 2. Imágenes de Rx AP y axial de cadera que muestran la osteosíntesis fallida a causa de la infección.

A los 10 días de la retirada del material, la evolución de la paciente sigue sin ser favorable, no llegando a disminuir los marcadores de infección en las analíticas, por lo que solicitamos estudio de TC donde se visualiza progresión de la infección por todo el músculo sartorio izquierdo. Se decide entonces realizar una nueva limpieza y desbridamiento quirúrgico aportando perlas de sulfato cálcico en la zona quirúrgica recubiertas de Gentamicina y Vancomicina, estas se distribuyen en el canal femoral y en todo el recorrido del sartorio. (Fig. 3 y 4 ).
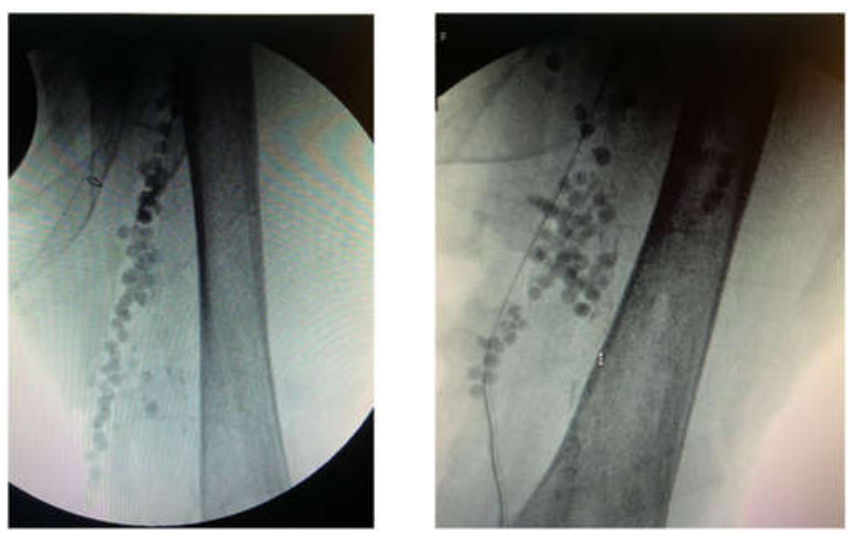

Figuras 3 y 4 . Imágenes de la escopia quirúrgica en las que se ven las perlas de sulfato cálcico en el recorrido del sartorio.

Se realiza un nuevo TC a los 15 días de este procedimiento apreciándose mejoría de las colecciones infecciosas.

A los 25 días del ingreso la paciente es dada de alta con tratamiento antibiótico oral, con buen estado general y descenso de los parámetros analíticos de infección.

La paciente se mantiene en descarga durante 3 meses, durante ese periodo es preciso realizar un nuevo desbridamiento de la herida quirúrgica por una dehiscencia que se resuelve sin problemas.

Actualmente, a los 7 meses de la cirugía y el tratamiento con las perlas de sulfato cálcico recubiertas de antibiótico, se encuentra sin dolor, caminando con andador y con una $P C R<10$ y $V S G<30$. (Fig 5). 


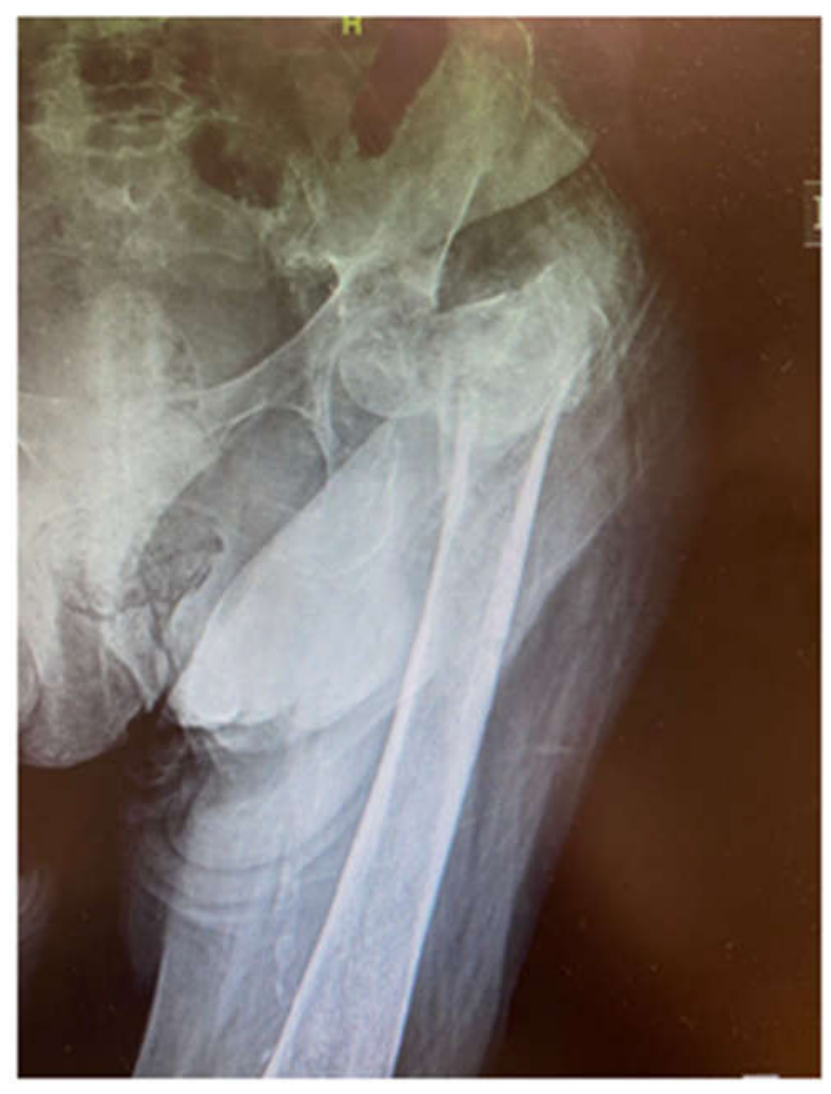

Figura 5. Rx AP actual de la cadera izquierda, sin dolor y caminando con andador, con la infección ya resuelta.

\section{DISCUSIÓN}

Las perlas de sulfato cálcico son un material absorbible, especialmente diseñado para rellenar los espacios muertos y colaborar en la estrategia de tratamiento de las infecciones cuyo uso está aprobado para utilizarse directamente en el sitio de infección ${ }^{1}$.
La preparación es simple, se mezcla el polvo que lleva la matriz de sulfato cálcico con la solución antibiótica y se introduce en un molde que proporciona la forma de perlas. Estas se introducen en el sitio de infección directamente con unas pinzas o a través de una jeringa a la que se puede cortar la punta para su fácil aplicación.

La liberación de los antibióticos administrados a través de la matriz de sulfato cálcico ha sido evaluada en diversos estudios en términos de niveles locales y sistémicos. Turner y colaboradores estudiaron la viabilidad de la tobramicina. Mientras que los niveles séricos eran indetectables tras las primeras 24 horas, los niveles locales de antibiótico se elevaban durante las primeras 24 horas para después disminuir de forma rápida y mantenerse presentes hasta los 14-28 días, lo que permitía el control de las posibles infecciones asociadas ${ }^{2-3}$.

Una de las ventajas de usar este tratamiento con respecto a otros como el cemento con antibióticos es el de reducir las intervenciones quirúrgicas ya que no requiere de su extracción al ser reabsorbible ${ }^{4}$.

Los efectos de este tratamiento son también eficaces en otras patologías frecuentes en traumatología como la osteomielitis crónica $^{5-6}$.

\section{CONCLUSIONES}

El tratamiento con perlas de sulfato cálcico recubiertas de antibiótico nos permite una liberación local, controlada y dirigida de antibiótico en el lugar concreto de la infección, además, su uso, potencia la formación ósea al reabsorberse, siendo un tratamiento de gran utilidad en infecciones asociadas a fracturas $y$ osteomielitis. 


\section{Bibliografía}

1. de Caso, J., Carrera, I., Masdeu, M. G., Millán, A., Moya, E., Toro, Á. et al. Stimulan®: Profilaxis antibiótica en las fracturas de la meseta tibial.

2. McNally $\mathbf{M}$ and Sendi P. Implant-Associated Osteomyelitis of long bones. In:. Bone and joint infections. From microbiology to diagnostic and treatment. First edition. Edited by Werner Zimmerli. Published 2015 by John Wiley and Sons, Inc. Chapter 20.p303-3

3. Turner TM, Urban RM, Hall DJ, Chye PC, Segreti J, Gitelis S. Local and systemic levels of tobramycin delivered from calcium sulfate bone graft substitute pellets. Clin Orthop Relat Res 2005; 437:97-104. http://www.ncbi.nlm.nih.gov/pubmed/16056033.

4. Thomas DB, Brooks DE, Bice TG, DeJong ES, Lonergan KT, Wenke JC. Tobramycin-impregnated calcium sulfate prevents infection in contaminated wounds. Clin Orthop Relat Res 2005; 441:366-71.

5. McKee MD, Li-Bland EA, Wild LM, Schemitsch EH. A Prospective, Randomized Clinical Trial Comparing an Antibioticlmpregnated Bioabsorbable Bone Substitute With Standard Antibiotic-Impregnated Cement Beads in the Treatment of Chronic Osteomyelitis and Infected Nonunion. J Orthop Trauma 2010; 24(8):483-90. doi:10.1097/BOT.0b013e3181df91d9

6. Ariza $\mathbf{J}$, Cobo $\mathbf{J}$, Baraia-Etxaburu $\mathbf{J}$ et al. Executive summary of management of prosthetic joint infections. Clinical practice guidelines by the Spanish Society of Infectious Diseases and. Clinical Microbiology (SEIMC). Enfermedades Infecciosas y Microbiología Clínica 2017; 35(3): 189-95. 